\title{
Temporal Geobiotic Mapping: A conceptual mapping technique toward visualising geobiotic areas in cross-section
}

\author{
Malte C. Ebach ${ }^{1}$, Giovanni Di Virgilio ${ }^{1} \&$ Shawn W. Laffan ${ }^{1}$
}

${ }^{1}$ School of Biological Earth and Environmental Sciences, University of New South Wales, Kensington, NSW 2052, Australia. mcebach@unsw.edu.au

\begin{abstract}
Temporal Geobiotic Mapping: A conceptual mapping technique toward visualising geobiotic areas in cross-section. Geobiota are defined by taxic assemblages (i.e., biota) and their defining abiotic breaks, which are mapped in cross-section to reveal past and future biotic boundaries. We term this conceptual approach Temporal Geobiotic Mapping (TGM) and offer it as a conceptual approach for biogeography. TGM is based on geological cross-sectioning, which creates maps based on the distribution of biota and known abiotic factors that drive their distribution, such as climate, topography, soil chemistry and underlying geology. However, the availability of abiotic data is limited for many areas. Unlike other approaches, TGM can be used when there is minimal data available. In order to demonstrate TGM, we use the well-known area in the Blue Mountains, New South Wales (NSW), south-eastern Australia and show how surface processes such as weathering and erosion affect the future distribution of a Moist Basalt Forest taxic assemblage. Biotic areas are best represented visually as maps, which can show transgressions and regressions of biota and abiota over time. Using such maps, a biogeographer can directly compare animal and plant distributions with features in the abiotic environment and may identify significant geographical barriers or pathways that explain biotic distributions.
\end{abstract}

KEYWORDS. Biostrata; Blue Mountains; Geobioic Mapping; Geobiota; Taxic Assemblages.

When Lamarck \& de Candolle (1805) published their Carte Botanique de France, naturalists were able to "see" distributions of taxic assemblages, herein biota, for the first time. The colourful map represented both the French flora and the abiotic processes that were inferred to have driven the distribution patterns. They identified the abiotic factors as:

"1. Temperature, as determined by distance from the equator, height above sea level and southern or northerly exposure.

2. The mode of watering, which is more or less the quantity of water that reaches the plant. The manner by which water is filtered through the soil and the matter that is dissolved in the water which may or may not be harmful to the growth of the plant.

3. The degree of soil tenacity or mobility"

(Lamarck \& de Candolle 1805, translation from Ebach \& Goujet 2006: 768).

While de Candolle later rejected these abiotic factors in favour of another, elevation (de Candolle 1820, see Nelson 1978), biogeographical mapping became the main way to depict distributions of taxic assemblages. These types of maps produced in the latter half of the 19th century followed in the same vein as that of de Candolle until more detailed studies in the 20th century revealed complications, such as overlapping areas and transition zones (see Morrone 2009). Maps, likewise, focused on representing biota in the present time and ignored past distributions. Palaeogeographers, for example, produced a series of maps of the same area in time intervals (Scotese 1997). In doing so, palaeobiogeographers had to com- pare geological, topographical, and climatic maps as well as the distributions of biota over time (see Young 1995, 2010), a practice that is absent in present-day historical biogeography, which relies heavily on phylogenetic and area relationships. How then, do we map a biotic area to reflect changes across time and space? The first step is to confirm that the area is in fact a natural area (see Parenti \& Ebach 2009). Once a historical biogeographical analysis confirms a biotic area to be a natural area, as opposed to an arbitrary cosmopolitan amalgamation of different areas, we may ask a number of questions. For example, what are the characteristics of a biotic area, regardless of its size, and what are its dimensions through time? Do biotic areas have sharply defined boundaries, or do they shift and overlap through time? Are biotic areas expanding or decreasing in size? In order to shed some light on these questions, we have devised a conceptual approach to biotic mapping that is derived from field geology.

Biostrata. A Conceptual Approach. We introduce a new concept for biogeography: to visualise a geobiotic area in crosssection, namely a biostratum. The same geographical area, over time, may change in biotic and abiotic composition, thereby having multiple temporally overlapping geobiotic areas. A cross-section through a number of these temporally overlapping geobiota create biostrata, which are the implementational equivalent to geological cross-sections. Geological cross-sections are reconstructions of the underlying lithology of a geographical place. The reconstruction can for example determine the shape of the folding and direction of faulting. Moreover, cross-sections can hypothesise the direction of denuded lithologies. Such geological reconstructions may also delimit the 
position of transgressing and regressing shorelines over time. Applied at the level of geobiotic distributions, biostrata may show the regression and transgression of taxic assemblages (biota) and their abiotic barriers through time. However, in order to do this we need to understand the influences of abiotic factors (sensu Lamarck \& de Candolle 1805), such as underlying geology, soil types, climate, erosion and weathering rates on biotic distributions and also the adaptability of taxic assemblages. Herein we use the term geobiota (sensu Morrone 2009), namely the interaction between biota and the abiotic factors that determine their distributions (see Table I for comparison). Many abiotic factors, like topography, elevation, pedodiversity, drainage, weathering and erosion, are dependent on two critical factors - climate and underlying geology. Of these two factors, underlying geology is the most likely known abiotic factor, while climate is either modelled for certain areas or limited to meteorological records. Since many areas have little to no climatic modelling, erosional history or palaeogeographical reconstruction, we propose a way to map simply using the minimum amount of information available. In order to determine what that minimum information is, we propose a set of principles that may help us understand what shapes a biota. Hence, for the purpose of this conceptual proposal: 1) Surface geology is predictable (i.e., we may predict the future surface geology based on erosion rates). 2) Surface geology influences topography, soils and hydrology. 3) Surface geology is amenable to retrodiction (i.e., we can model for past surface geology, including volcanism and orogeny).

There is already a multitude of methods available that attempt to assess the intricate impact of abiota on vegetation, individual taxic distributions and ecosystems (Bertrand 1969; Cotterill \& de Wit 2011; Goodier et al. 2011; Huggett 1995; Kiage \& Lui 2009; Moreno et al. 2012). Our conceptual approach, however, intends to hypothetically map taxic assemblages of any geographical size through time in a single cross-section. Our approach can be used as a basic hypothetical framework for pursuing further palaeogeographical and palaeoecological inquires.

Table I. Concepts, patterns and processes explored in taxa, biota, geobiota and geographical areas.

\begin{tabular}{|l|l|l|l|l|}
\hline & Taxa & Biota & Geobiota & Areas \\
\hline Population dynamics and species concepts & & & & \\
\hline Endemism and single species distributions & & & & \\
\hline Physiological suitably to abiotic landscape & & & & \\
\hline Multiple overlapping taxic distributions & & & & \\
\hline Physical and chemical attributes of boundaries & & & & \\
\hline Geological and geographical processes & & & & \\
\hline
\end{tabular}

\section{Temporal Geobiotic Mapping (TGM): A proposed mapping technique for historical biogeography}

To map geobiota and form hypotheses about their dimensions over time are the underlying aims of Temporal Geobiotic Mapping (TGM).

As a method to map hypothetical geobiota, TGM analyses known biotic and abiotic distributions (i.e., geology, ele- vation) in order to hypothesise their transgressions and regressions through time. Further data on factors such as water acidity, climatic factors such as rainfall and temperature, are additional and can only aid to streamline the approach. TGM requires a reasonable working knowledge of processes from various fields, including geography, petrology, pedology, hydrology, geomorphology, and biogeography. Consilience between the earth and biological sciences is rare, being mostly restricted to geography or palaeobiogeography. Because the discovery of geobiota requires both a multistage and consilient approach, TGM relies on mapping and geographical information systems (GIS) to analyse the vast amounts of data available. It is therefore vital that geobiota are mapped correctly in four dimensions, folding cross-sections and palaeoreconstructions into a single abstract diagram. Considering that TGM can theoretically be used in any area, only minimal amounts of data are required to create a potentially viable hypothesis.

The TGM method is as follows (as the data allows):

I) Map known data in the study area:

- Stage 1: Map all known taxic distributions.

- Stage 2: Map all known abiotic distributions (i.e., surface geology).

II) Hypothesise the past and future extent of the geobiotic area:

- Stage 3: Map past and future geological structures (e.g., bedding, faulting etc.).

- Stage 4: Map past and future geobiota.

The next step is to map all stages graphically to determine the degree of overlap between the biota and the abiotic landscape. Once this has been completed, the abiotic landscapes need to be mapped in order to identify biotic breaks that define the boundaries of one or more biota.

Identifying biota and biotic breaks. If the data is available it may be possible to quantify biotic breaks. One set of biotic breaks (and their abiotic attributes) may define a group of similar biota (Di Virgilio et al. 2012). Further methodological requirements, such as biotic and abiotic spatial turnover, need to be measured to determine the dissimilarities between biota on either side of a biotic break (Fig. 1).

The advantage of using both biotic and abiotic turnover is that identified biotic area(s) may be quantified as part of their diagnosis. For example, the Sydney Basin in Australia is dissimilar at its boundaries with the areas adjacent to it (Di Virgilio et al. 2012, 2013: fig. 1). By measuring the spatial turnover (i.e., compositional dissimilarity) for elevation, soils, surface geology and so on, we can determine which abiotic factors are at work at any given point along the Sydney Basin biotic bioregion. That is, more than one abiotic factor may constrain the biota at any time. Further measurements, such as sampling and redundancy rates, may be recorded to ensure that the data are sufficient to support a certain proportion of spatial turnover.

Using biostrata to predict future and past biotic distributions. The next phase of TGM is to assess the dimensions of the geobiotic boundaries through time. This requires 

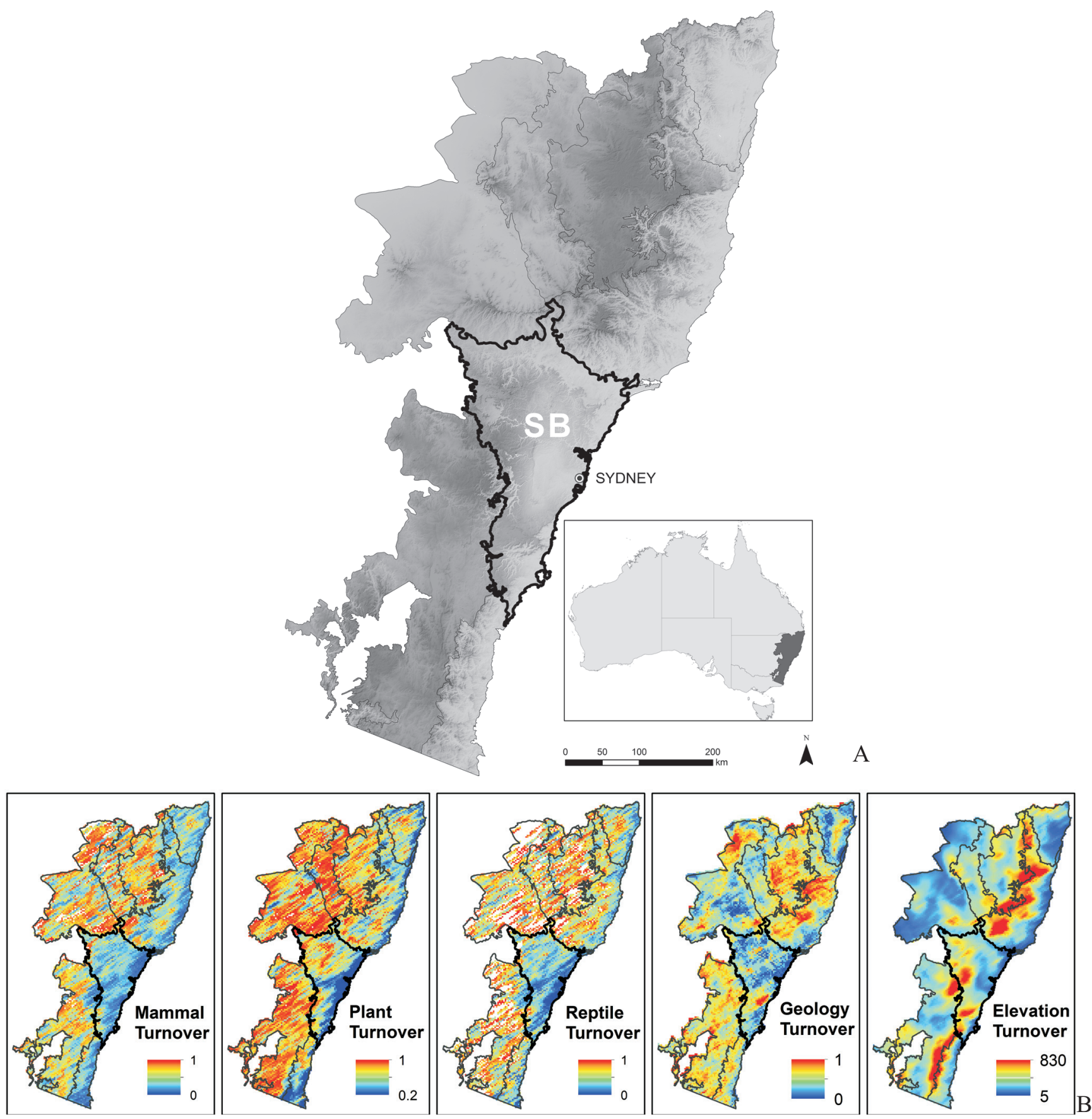

Fig. 1. A. Location of the Sydney Basin biogeographical region (SB) and surrounding bioregions in eastern New South Wales, south-eastern Australia in a study by Di Virgilio et al. (2012); B. Gradational biotic and environmental spatial turnover in the Sydney Basin and the surrounding biogeographic regions of eastern New South Wales, Australia (Di Virgilio et al. 2012).

a third or abstract 'dimension' to be mapped as a cross-section (Fig. 2). The third dimension is equivalent to a geological cross-section (Fig. 2a), which can be temporally "sliced" allowing for extrapolations across the cross-section. For instance, the upper part of the cross-section in Fig. 2c is oldest $\left(t_{-n}\right)$, while the lower half in Fig. 2e is youngest $\left(t_{+n}\right)$. The hypothetical example in Fig. 3 shows that Geobiota 1 becomes "extinct" over time as the basalt layer (Bs) erodes away (Fig. 3e). The underlying basalt no longer produces the soils necessary to support Geobiota 1, resulting in the range expansion of Geobiota 2, 3 and 4 into that space (Fig. 3b).

Extrapolating from a known geology, we are able to hypothesise the position of past geological strata. In addition, if we are able to determine historical climatic processes, erosion and weathering rates, we may propose the potential composition of past soils and measure topography (again, based on abiotic attributes such as denudation and lithology). The addition of a timescale makes it possible for biogeogra- 

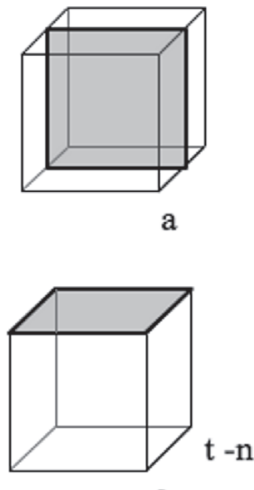

c

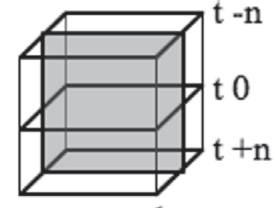

b

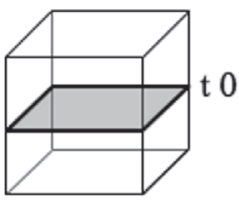

$\mathrm{d}$

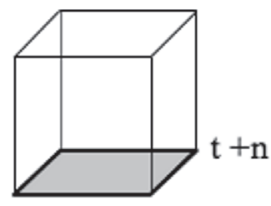

e
Fig. 2. Comparison of geological and geobiotic cross-sections. a. A geological cross-section; b. Geobiotic cross-section (shaded in grey). Each cross-section of a geobiota consists of a single biostratum. A complete cross-section contains three biostrata c-e. Geobiota at $\mathrm{t}-\mathrm{n}, \mathrm{t} 0$ and $\mathrm{t}+\mathrm{n}$ respectively.

phers to track geobiota through time, retrodicting the past boundaries and predicting potential future abiotic landscapes. At this point it is important to note that any additional data will greatly improve the hypothetical model. In Fig. 3, however, we are assuming the minimum amount of data, namely the extent of the geological and biotic distribution.

A note on scale. Temporal Geobiotic Mapping can be performed at any scale or spatial extent: from a continental extent incorporating large distribution patterns across many different geological terranes to fine extent analyses, such as a lake or rock outcrop. The method is theoretically designed to work on any sized biota, be it micro-organisms or marine shore-fishes. As long as the biota (taxic assemblage) is dependent on an abiotic landscape, the TGM should provide a biostratum along any sized cross-section.

\section{An example from the blue mountains in the Sydney Basin, Australia using tgm and minimal data}

In order to demonstrate the TGM concept using minimal amounts of data, we have decided to use an area that has a known and documented erosional, geological and biotic record. The example is used in addition to the hypothetical example to show the limitations of TGM. With limited data, TGM can only make the most basic hypothetical assumptions. This example is an attempt at applying a concept at the most basic level, however, it is not an attempt to make a detailed assessment of the ecology or ecophysiology of the flora of the Blue Mountains. This should be left to future analyses that have far more data and a quantified application of the TGM approach. Our example only acts as a conceptual approach to demonstrate how the TGM technique works in theory. The geology of the Sydney Basin region in eastern Australia may be used to hypothesise geobiotic distributions using the TGM approach.

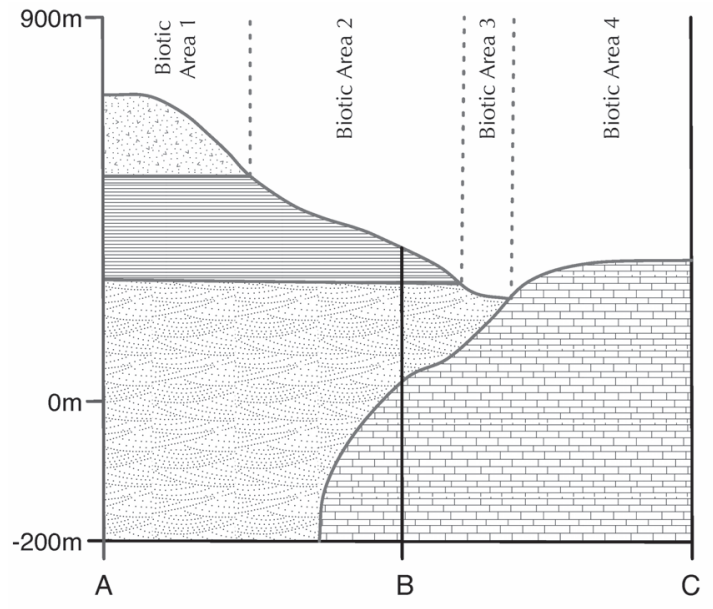

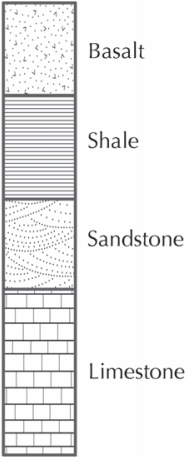

(a)
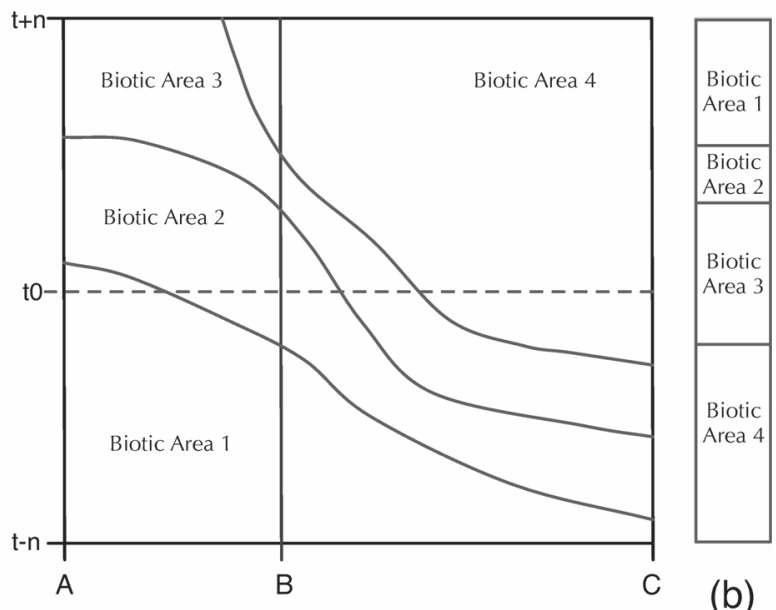

(b)

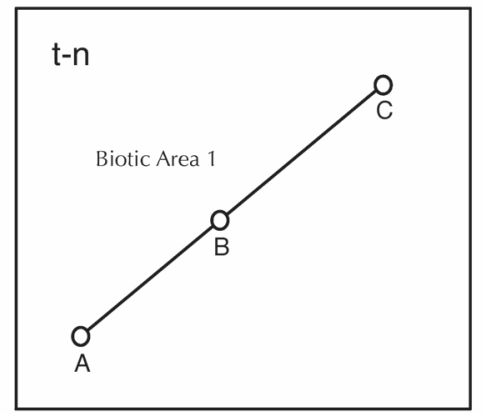

(c)

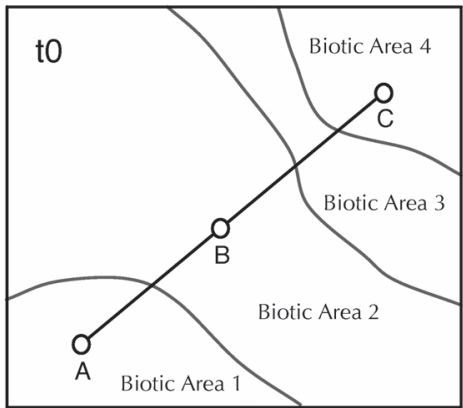

(d)

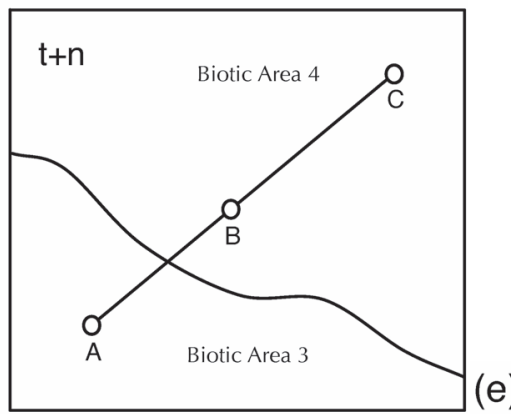

Fig. 3a. A geological cross section showing the underlying geology between points $\mathrm{A}$ and $\mathrm{B}$ at time t0. Point $\mathrm{C}$ represents a single point of interest; $\mathrm{b}$. A biogeographical cross-section (biostrata) between points A and B across time ( $\mathrm{t}-\mathrm{n}$ to $\mathrm{t}+\mathrm{n}$ ) extrapolated from the geological cross-section and estimated rates of erosion and geological change; c-e. The biotic distributions of the current time (t0), past ( $\mathrm{t}-\mathrm{n})$ and future $(\mathrm{t}+\mathrm{n})$. 
Background. The Sydney Basin, formed during the Permian to Triassic, lies over the older Devonian Lachlan Fold Belt and consists of a Neogene basalt layer (van der Beek et al. 2001). The Sydney Basin, almost cake-layered and devoid of extensive folding, has a general lateral erosion plane that has led to a predominantly Triassic sandstone layer that forms a plateau with steep escarpments. Several of these escarpments reach over $900 \mathrm{~m}$ above sea level and form the Blue Mountains, well known for their endemic fauna and flora as well as a dramatic landscape of plateaus and deep gorges.

Much of the Neogene basalt layer has been weathered away, leaving basalt caps that dot the basin, each sharing a unique taxic assemblage called Moist Basalt Cap Forests (Keith \& Benson 1988). The rest of the basin comprises biotic units adapted to the sandstone or Permian shale layers, with several swamps of the side of escarpments and rainforest in deep gullies and gorges (Downing et al. 2007). The Sydney Basin has undergone extensive volcanic activity between $14 \mathrm{Ma}$ to $20 \mathrm{Ma}$, leaving a 200m thick basalt layer across much of its extent (van der Beek et al. 2001). Weathering and erosion has removed much of the basalt, creating uplift of the entire basin. The underlying Triassic rock has, prior to the Neogene, undergone significant erosion, leaving large protogorges that mirror the gorges of today. The subsequent erosion would suggest that the Sydney Basin has been undergoing constant uplift, and accounts for the major discrepancies between Permian and Triassic marine sediments lying above $900 \mathrm{~m}$ in relation to current sea level. Uplift due to massive erosion over $100 \mathrm{Ma}$ is regarded accountable for this great contrast.

Geobiotic Area. For the purposes of this conceptual demonstration, we focus on three basalt capped peaks in the upper Blue Mountains, between Blackheath and Bilpin (transect of $\sim 15 \mathrm{~km}$ ) to demonstrate the TGM method (Fig. 4).

Available Data. The geology of the upper Blue Mountains provides three main soil types that are associated with Moist Basalt Cap Forests, Sandstone Forests and Shale Forests (Keith \& Benson 1988). The underlying sandstone creates a dry, well-drained, sandy soil that is low in nutrients (Tozer et al. 2010). The Sandstone Forest biotic unit will become predominant over time, as slow weathering away from the eastern coastline reveals the Permian clay shales below. The geobiota are located between 500-1000m above sea level and located within a temperate climate.

The Moist Basalt Cap forests lie on a rich and fertile basalt soil, derived from the Neogene basalt layer. These forests consist of Eucalyptus viminalis (ribbon gum), E. blaxlandii (brown stringybark) and E. radiata (narrow-leaved peppermint). Other canopy species that may be encountered include E. cypellocarpa (monkey gum), E. oreades (blue mountain ash) and E. fastigata (brown barrel) (see Tozer et al. 2010). In total there are three basic biotic units: Moist Basalt Cap Forest (Biota A), Sandstone Forest (Biota B) and Shale Forests (Biota C). Other vegetative types, such as hanging swamps are not included due to their small size and limited ranges.

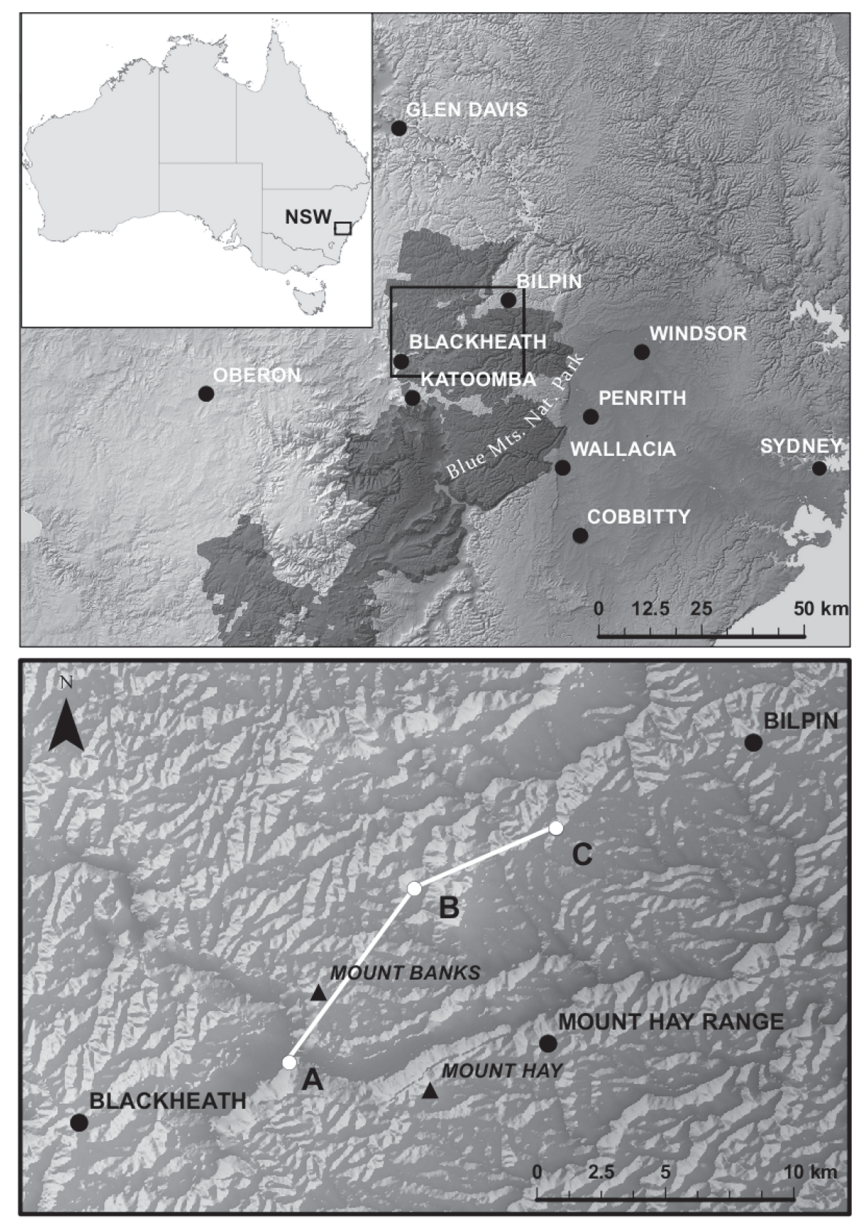

Fig. 4. Location of the study area in the Blue Mountains $100 \mathrm{~km}$ west of Sydney, New South Wales, Australia.

TGM Approach. We implement the TGM manually as there are no known algorithmic approaches. The approach is appropriate considering the low amount of data and the highly conceptual nature of the application.

I) Map known data (Stages 1 and 2). The geological crosssection shows the cake-layered lithology upon which each taxic assemblage is located. Elevation is also mapped on the geological cross-section. Given that we do not have accurate measurements for weathering and erosion, we are unable to hypothesise the past and future elevation.

II) Hypothesise the past and future extent of the geobiotic area (Stages 3 and 4). The geological cross-section shows no monoclines, faulting or folding, thereby making it easy to match past lithology across current gorges. For example, the Hawkesbury Sandstone (Rh) of Mount Banks and Mount Bell were at one time connected lithologically (Fig. 5). In addition, the three biotic units associated with Neogene basalt, Triassic sandstones and Permian shales will at some stage have existed between Mount Banks and Mount Bell. Since there is no other information to contradict this presumption, the hypothesis is seemingly "uniformitarian" in nature.

Given that we now have associated both the lithologies with the biota and have ascertained the simple premise that the 


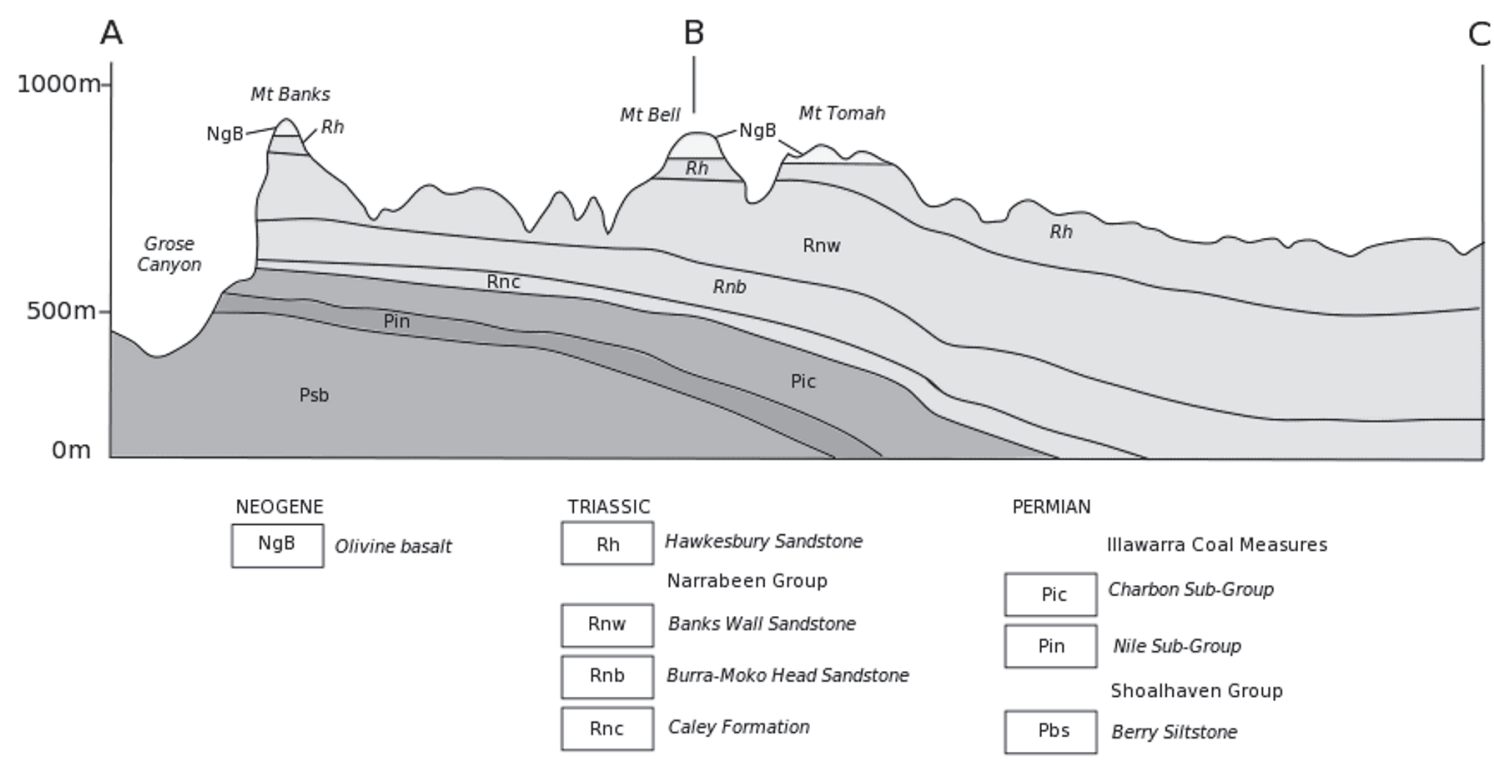

Fig. 5. A cross section of points A to C in Fig. 3. Modified from Bembrick (1980: Fig 8.3).

lithologies of either side of Mounts Banks, Bell and Tomah were at one stage continuous, we may convert the biotic and abiotic data into geobiota. In doing so, we reveal biostrata (Fig. $6 a)$ and map the extent of geobiotic distribution over time (Fig. $6 b-d)$. Note that the TGM technique does not indicate palaeoelevation, only potential past and future distribution.

Limitations. The cross-sections produced by the TGM are limited by the amount of data available. At the most basic level, TGM will simply extend and match lithologies as in any geological cross-section. While this might be a very basic concept, it becomes fundamental if a whole suite of geo- graphical factors are associated with a known lithology. For instance, if we can ascertain that a certain type of sandstone produces a sandy-loam well-drained soil, with certain hydrological and chemical characteristics as well as climatic data or models, we may be able to determine denudation rates. While this will give us a better indication of the abiotic landscape, it can provide us with enough characteristics to define the type of flora and fauna that may have lived there based on existing taxa.

TGM is simply a conceptual framework for a much larger algorithmic-based approach that can quantify biotic and abi-

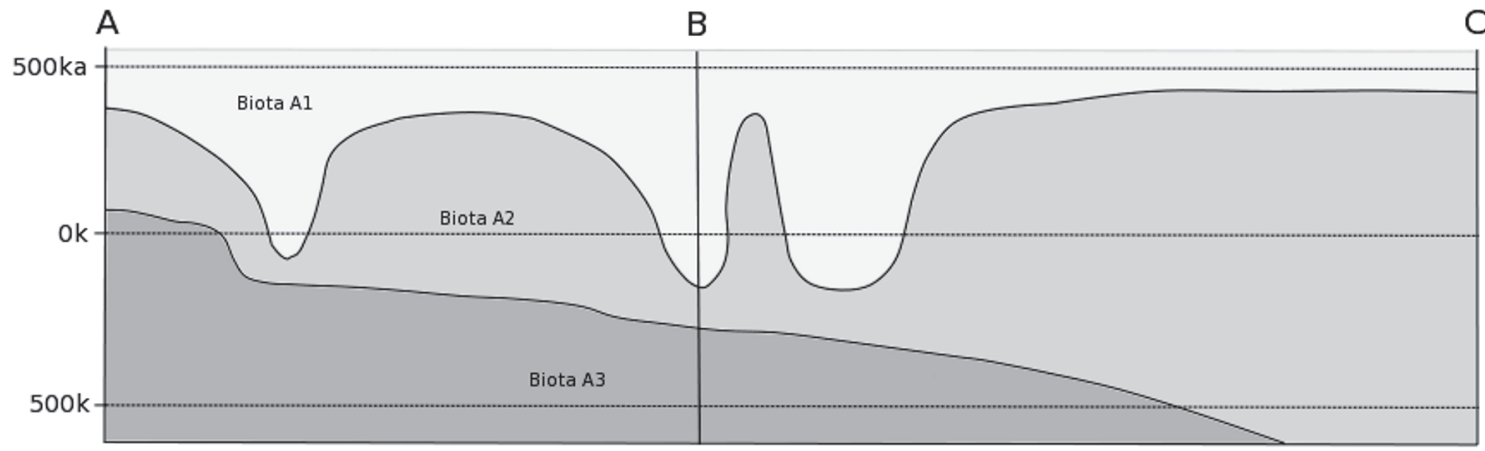

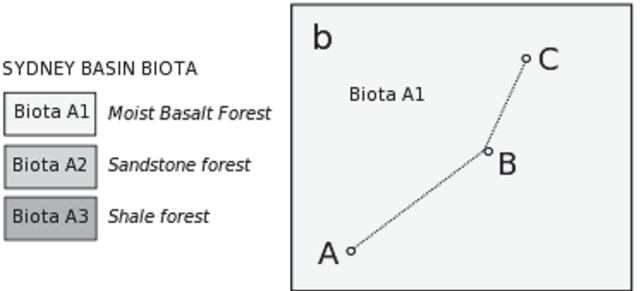

$500 \mathrm{ka}$

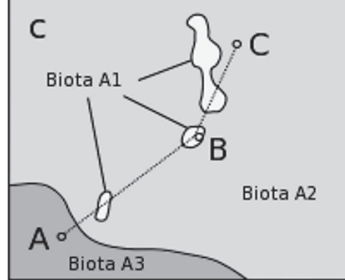

Ok

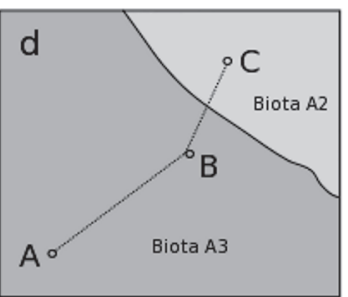

$500 \mathrm{k}$

Fig. 6a. Biostrata of geobiota A1-A3. Geobiota A1 consists of the biotic unit 'Moist Basalt Forest' and Neogene basalt (see Fig. 4); Geobiota 2 is Sandstone Forest and Triassic sandstones; Geobiota A3 is Shale Forest and Permian mudstone and siltstones; b. Geobiota present along A-C 500k years ago; c. Present day geobiota in the same area; d. A future distribution of geobiota A2 and A3 after A1 has become extinct with the study area. 
otic data. However, given that many areas in Australia and across the world have little data available, TGM may only be applied at a basic level to create maps and hypothetical crosssections. The most basic data generally tends to consist of taxic distributions, soils types and geology, meaning that a manual TGM analysis can be applied to map the temporal distributions of geobiota through time.

\section{CONCLUSION}

Biogeographers can map hypothetical geobiotic areas derived from Temporal Geobiotic Mapping (TGM) using the most basic data. Although TGM is limited by available data, it can be used to create maps of hypothetical temporal crosssections. Further discoveries and new data may only improve these hypotheses.

The future of biogeography lies in providing empirical descriptions, models and hypotheses that are based on a basic premise that Life and Earth evolve together. With that premise alone, it is possible to create even the most basic maps using as little data as possible, potentially allowing biogeographers to glimpse at the hypothetical past and future distributions of their biota. TGM is only a basic concept that may lead to future algorithmic implementations that can process a high volume of data. Whether done by hand or implemented by computer, TGM is a simple conceptual approach that is available for the biogeographical community to understand the past and future distributions of biotic areas.

\section{ACKNOWLEDGEMENTS}

We thank Gary Nelson, Lynne Parenti for reading through previous versions of the manuscript. We also thank Brian Rosen and Andrés Moreira Muñoz for their valuable comments and Melinda L. Tursky for her help with figures. MCE was supported under Australian Research Council's 'Future Fellow' funding scheme (project number FT0992002). MCE also wishes to thank the University of New South Wales, Australia for two Goldstar Grants (RG114989 \& RG124461).

\section{REFERENCES}

Bembrick, C. 1980. Geology of the Blue Mountains, western Sydney Basin, p. 134-161. In: Herbert, C. \& Helby, R. (eds.). A guide to the Sydney Basin. Geological Survey of New South Wales Bulletin 26, 588 p.

Bertrand, G. 1971. Écologie de l'espace géographique. Recherches pour une "science du paysage" Compte Rendu des Seances de la Societe de biogeographie 406: 195-205.

Candolle, A.P. de. 1820. Essai elementare de geographie botanique. Dictionnaire des Sciences Naturelles, Volume 18. Paris, F. Levrault, 64 p.
Cotterill, F.P.D. \& de Wit, M.J.G. 2011. Geoecodynamics and the Kalahari epeirogeny: linking its genomic record, tree of life and palimpsest into a unified narrative of landscape evolution. South African Journal of Geology 114: 489-514.

Di Virgilio, G., Laffan, S.W. \& Ebach, M.C. 2012. Fine scale quantification of floral and faunal breaks and their geographic correlates, with an example from south-eastern Australia. Journal of Biogeography 39: 1862-1876.

Di Virgilio, G., Laffan, S.W. \& Ebach, M.C. 2013. Quantifying high resolution transitional breaks in plant and mammal distributions at regional extent and their association with climate, topography and geology. PLoS One 8: e59227.

Downing, A.J., Brown, E.A., Oldfield, R.J., Selkirk, P.M. \& Coveny, R. 2007. Bryophytes and their distribution in the Blue Mountains region of New South Wales. Cunninghamia 10: 225-254.

Ebach, M.C. \& Goujet, D.F. 2006. The first biogeographical map. Journal of Biogeography 33: 761-769.

Goodier, S.A.M., Cotterill, F.P.D., O’Ryan, C., Skelton, P.H. \& de Wit, M.J. 2011. Cryptic diversity of African tigerfish (Genus Hydrocynus) reveals palaeogeographic signatures of linked Neogene geotectonic events. PLoS ONE 6: e28775.

Huggett, R.J. 1995. Geoecology: An Evolutionary Approach. London, Routledge, $344 \mathrm{p}$.

Keith, D.A. \& Benson, D.H. 1988. The natural vegetation of the Katoomba 1: 100000 map sheet. Cunninghamia 2: 107-144.

Kiage, L.M. \& Liu, K. 2009. Paleoenvironmental changes in the Lake Baringo Basin, Kenya, East Africa since AD 1650: Evidence from the Paleorecord. Professional Geographer 61: 438-458.

Lamarck, J.-B. de M. de \& Candolle, A.P. de. 1805. Explication de la carte botanique de la France, p. i-xii. In: Flore Française, ou descriptions succinctes de toutes les plantes qui croissent naturellement en France: Disposees selon une nouvelle methode d'analyse, et precedees par un expose des principes elementaires de la botanique. 3rd ed., Vol. 2. Paris, Desray, xii +600 p.

Moreno, P.I., Villa-Martínez, R., Cárdenas M.L. \& Sagredo, E.A. 2012. Deglacial changes of the southern margin of the southern westerly winds revealed by terrestrial records from SW Patagonia $\left(52^{\circ} \mathrm{S}\right)$. Quaternary Science Reviews 41: 1-21.

Morrone, J.J. 2009. Evolutionary biogeography: An integrative approach with case studies. New York, Columbia University Press, xvi+301 p.

Nelson, G. 1978. From Candolle to Croizat: comments on the history of biogeography. Journal of the History of Biology 11: 269-305.

Parenti, L.R. \& Ebach, M.C. 2009. Comparative Biogeography: Discovering and Classifying Biogeographical Patterns of a Dynamic Earth. Berkeley, University of California Press, xiii+292 p.

Scotese, C.R. 1997. Continental Drift (7th edition). Arlington, Texas, PALEOMAP Project, $79 \mathrm{p}$.

Tozer, M.G., Turner, K., Keith, D.A., Tindall, D., Pennay, C., Simpson, C., MacKenzie, B., Beukers, P. \& Cox, S. 2010. Native vegetation of southeast NSW: a revised classification and map for the coast and eastern tablelands. Cunninghamia 11: 359-406.

van der Beek, P., Pulford, A. \& Braun, J. 2001. Cenozoic landscape development in the Blue Mountains (SE Australia): Lithological and tectonic controls on rifted margin morphology. Journal of Geology 109: 35-56.

Young, G.C. 1995. Application of cladistics to terrane history-parsimony analysis of qualitative geological data. Journal of Southeast Asian Earth Science 11: 167-176.

Young, G.C. 2012. Analytical methods in palaeobiogeography, and the role of early vertebrate studies. Palaeoworld 19: 160-173. 